\title{
Rectal Stenosis
}

National Cancer Institute

\section{Source}

National Cancer Institute. Rectal Stenosis. NCl Thesaurus. Code C78589.

Narrowing of the rectal lumen. 